\title{
Desenvolvimento de Interface em MATLAB para Aprendizado e Comparação de Métodos Numéricos
}

\author{
Duaymy B. R. Góes Giovane M. da Silva Danielle L. Guedes \\ Universidade Federal do Pará - Faculdade de Engenharia Elétrica \\ 66075-110, Campus Guamá, Belém, PA \\ E-mail: petee@yahoogroups.ufpa.br \\ Orlando Fonseca Silva \\ Universidade Federal do Pará - Faculdade de Engenharia Elétrica \\ 66075-110, Campus Guamá, Belém, PA \\ E-mail: orfosi@ufpa.br
}

\begin{abstract}
RESUMO
Quando se quer resolver um problema em engenharia deve-se ter em mente o modelo que representa a situação física. Tal modelo é transformado em equações matemáticas, modelo matemático, que será resolvido ou por métodos analíticos, ou por numéricos. Como para a maioria das situações não há soluções analíticas, os métodos numéricos tornam-se a alternativa mais econômica para esse tipo de problema, visto que estas podem ser empregadas sem maiores dificuldades. No entanto, as frequentes mudanças de parâmetros, combinadas a várias iterações constituem uma dificuldade. A utilização de um ambiente computacional, como por exemplo o MATLAB, permite contornar tal empecilho, além de proporcionar precisão e velocidade. Dessa forma, o presente trabalho tem por objetivo desenvolver uma interface gráfica capaz de otimizar a utilização de métodos numéricos.

A primeira etapa do projeto baseou-se na elaboração de rotinas para vinte e dois métodos, utilizando-se o ambiente MATLAB, agrupados em cinco categorias. Na segunda etapa focou-se no desenvolvimento de interfaces gráficas de acordo com cada categoria de rotina. Para isso, utilizou-se a ferramenta guide, a qual inicia um editor interativo para criação e edição de interfaces, apresentando um conjunto de ferramentas que facilitam a manipulação dos objetos necessários ao seu desenvolvimento. A princípio, devido ao grande número de métodos, foram desenvolvidas interfaces em janelas gráficas individuais para posteriormente realizar-se a integração de todas em uma única janela, permitindo ao usuário a utilização, paralelamente, de métodos diferentes.

A estrutura criada para a integração dos métodos consistiu na utilização de um grupo de painéis, sendo que, cada painel abriga a interface de um determinado método. No MATLAB, a função uipanel permite a criação de um objeto do tipo painel, que funciona como um elemento que agrupa botões, eixos e tabelas, sendo esses últimos associados ao primeiro. Desse modo, foi possível a habilitação de um painel e a omissão dos outros. Essa estrutura permite a existência de várias interfaces em uma mesma janela gráfica. Para a exibição de um método em específico, utilizou-se a função uimenu, a qual cria uma barra de menus, com hierarquias de menus e submenus, sendo que cada menu corresponde a uma categoria de métodos.

Concluída a fase de gerenciamento para a exibição de painéis, iniciou-se a construção de uma barra de ferramentas com as funções zoom, cursor de dados e a ferramenta mão, a qual disponibiliza opções para análise de resultados obtidos e edição da interface principal. Disponibilizou-se, também, a possibilidade de visualização de dois painéis em simultâneo para comparação de resultados com dois métodos diferentes. Para permitir a inserção de novas classes e métodos, foi desenvolvido um assistente que carrega o arquivo mfile contendo sua interface e programação. Outra opção é exportar os métodos, ou seja, criar um arquivo contendo a interface do método em uma janela gráfica individual. A interface principal, assim como o assistente para sua edição, são apresentados na Figura 1.
\end{abstract}




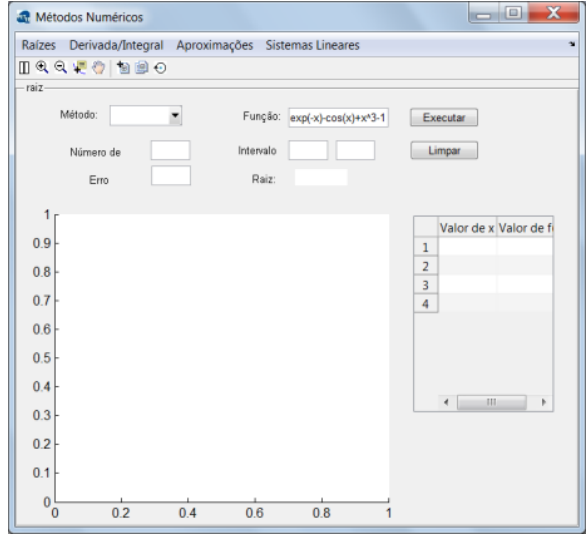

(a)

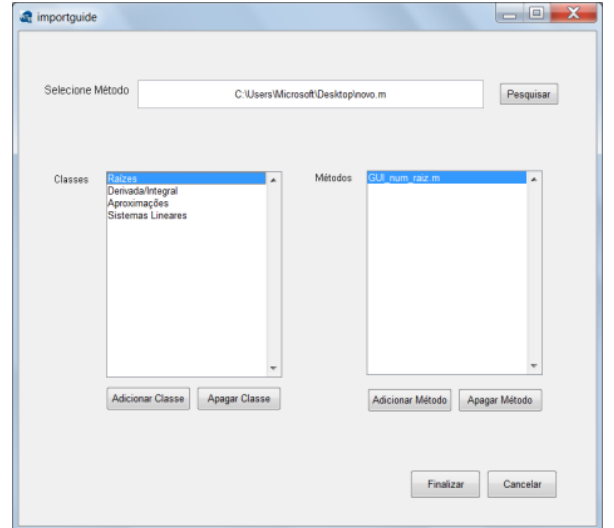

(b)

Figura 1: (a) Interface Principal e (b) assistente para sua edição.

Com a interface principal construída, iniciou-se a inserção das classes e métodos através do assistente. A primeira classe, a dos métodos iterativos para o cálculo de raízes reais, obteve resultados aproximados. Na segunda, é possível fazer a diferenciação numérica por 3 métodos Método da Diferença Central, Progressiva e Regressiva - e também é possível fazer a integração numérica por 3 métodos, o Método do Trapézio, o Método de Simpson e o Método de Simpson Repetido. Na terceira, criou-se uma classe para os métodos de aproximação e interpolação, contando com uma aba para os discretos (Figura 2) e outra para contínuos. A última categoria agrupou métodos diretos e iterativos para solução de sistemas de equações lineares. Para os métodos diretos a interface gráfica construída foi limitada para sistemas de até 3 equações e 3 incógnitas, enquanto para os iterativos também para há espaço para valor inicial e o erro relativo. Em todos os exemplos aplicados, os resultados concordaram com a teoria.
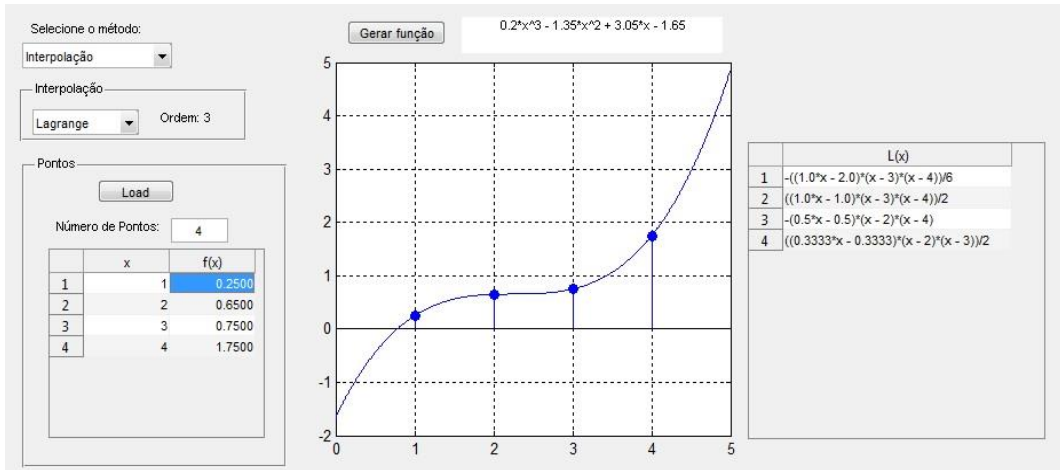

Figura 2: Cálculo de função de interpolação pelo método de Lagrange.

Palavras-chave: Criação de Interfaces, Métodos Numéricos, Ensino.

\section{Referências}

[1] “MATHWORKS PRODUCTS AND SERVICES”, disponível em: www.mathworks.com

[2] RÉGIS, S. Q., BORTOLI, A. L. Fundamentos de Cálculo Numérico para Engenheiros. Porto Alegre, dezembro de 2009.

[3] RUGGiero, M. A. G., LOPES, V.L.R. Cálculo Numérico: Aspectos Teóricos e Computacionais - Pearson, 1996. $422 \mathrm{p}$.

[4] SPERANDIO, D., MENDES, J. T., MONKEN, L. H. Cálculo Numérico: Características Matemáticas e Computacionais dos Métodos Numéricos - Pearson, 2003. 368 p. 